\title{
Stimulation of Germination of Bacterial Spores by Analogues of $\mathrm{D}$-Alanine
}

\author{
By A. JONES* AND G. W. GOULD \\ Unilever Research Laboratory, Colworth House, Sharnbrook, Bedford
}

(Accepted for publication I May I968)

SUMMARY

\begin{abstract}
L-Alanine-initiated germination of spores of Bacillus cereus was potentiated by the following structural analogues of alanine: $O$-carbamyl-D-serine (OCDS), D-cycloserine (DCS), $\beta$-alanylhydroxamic acid ( $\beta$ AHA) and glycyl hydroxamic acid (GHA); but not by $D$ - $\alpha$-alanyl-hydroxamic acid (DAHA). Potentiation of germination resulted from inhibition of alanine racemase in the spores with consequent suppression of the formation of D-alanine, an inhibitor of L-alanine-initiated germination. OCDS was the most effective potentiator of germination and inhibitor of racemase. $\beta$ AHA and GHA were more effective potentiators of germination than could be explained solely by their weak inhibition of the racemase. The extra effectiveness was associated with slow binding of the analogues to the spores, and possibly also with formation of hydroxylamine which also inhibited alanine racemase and potentiated L-alanine-initiated germination. Germination initiated by ribosides and amino acids other than L-alanine was not strongly potentiated by OCDS, arguing against a role for L-alanine as an intermediate. However, germination initiated by adenosine $+D$-alanine was strongly inhibited by OCDS, which argues for the role of $D$-alanine being to supply the $L$-isomer by racemization. Antibacterial activities of the analogues did not mirror their activities as potentiators of germination.
\end{abstract}

\section{INTRODUCTION}

Since the pioneering work of Hills (1949, 1950) the importance of L-alanine as an initiator and D-alanine as an inhibitor of germination of many types of bacterial spores has been amply confirmed. Inhibition of L-alanine-initiated spore germination by D-alanine (Hills, I949) probably occurs because the D-isomer inhibits the enzyme which handles L-alanine, important in germination. This enzyme may be L-alanine dehydrogenase (O'Connor \& Halvorson, I 96 I $a, b$ ) or some other as yet unidentified enzyme (Freeze \& Cashel, 1965). That inhibitory D-alanine could be formed from L-alanine by the spores themselves was shown by the demonstration of alanine racemase activity in spores of Bacillus cereus $\mathrm{T}$ and other organisms (Stewart \& Halvorson, I953). Church, Halvorson \& Halvorson (1954) showed that spore germination and racemase activity could be dissociated from each other, for instance by change of $\mathrm{pH}$ value; racemase in spores therefore appeared normally to hinder rather than play a positive role in L-alanine-initiated germination, particularly with concentrated spore suspensions (Fey, Gould \& Hitchins, 1964). The magnitude of the hindrance was emphasized by Krask(I96I), who showed that D-cysteine stimulated L-alanine-initiated

* Present address: Department of Microbiology, University of Bradford, Yorkshire. 
germination of $B$. cereus $\mathrm{T}$ spores by inhibiting alanine racemase and thereby preventing formation of D-alanine, and by Gould (1966), who showed that two racemase inhibitors (D-cycloserine and $O$-carbamyl-D-serine) which are structural analogues of D-alanine stimulated L-alanine-initiated germination.

Substances which stimulate germination (and therefore heat- and radiation-sensitization) of spores might find useful application as spore-control agents in materials in which spores are normally present but unwanted (e.g. in most foodstuffs). We have therefore studied the action, on spore germination and on the activity of spore alanine racemase, of a number of alanine analogues, including optically inactive and D-stereroisomers, with L-alanine and other chemical agents as germinants.

\section{METHODS}

Spores. Spores of Bacillus cereus strain T were used for most experiments. Other organisms used were B. cereus PX (Hitchins, Gould \& Hurst, 1963); B. cereus NCTC 945 and $B$. megaterium NCTC $785 \mathrm{I}$ (National Collection of Type Cultures, Colindale); B. subtilis A (rough strain from F. F. Busta; Edwards, Busta \& Speck, I965); B. subtilis syn. globigii (Fey et al. 1964); B. pumilus S 3 , and B. polymyxa м I (laboratory isolates). Spores were grown on potato yeast-extract glucose agar at $37^{\circ}$ as described by Hitchins et al. (1963). When sporulation and lysis of sporangia was complete the spores were scraped from the agar, washed six times with cold distilled water by centrifugation and stored at $4^{\circ}$ in water at a concentration equivalent to about $20 \mathrm{mg}$. dry weight $/ \mathrm{ml}$. When heat-activated spores were required, samples of suspensions were heated at $70^{\circ}$ for $30 \mathrm{~min}$. immediately before use.

Media and measurement of germination. Germination media normally contained sodium phosphate $(80 \mathrm{~mm}, \mathrm{pH} 8 \cdot 0)$. The buffer was sodium acetate $(80 \mathrm{~mm}, \mathrm{pH} 8 \cdot 0)$ whenever calcium dipicolinate was used. Germinants and related compounds used (Koch-Light Laboratories Ltd., Colnbrook, Bucks) were L-alanine, D-alanine, L-cysteine (all IO $\mathrm{mM}$ ); inosine (0.2-I.0 mM); adenosine (I mM); adenosine (I mM for unheated, $100 \mu \mathrm{M}$ for heat-activated spores) $+\mathrm{L}$-alanine or other amino acids (I0 and I $00 \mu \mathrm{M}$ for unheated and heat-activated spores respectively); $n$-dodecylamine (I/5 saturated soution): calcium dipicolinate $(40 \mathrm{mM})$ was made by mixing sodium dipicolinate solution (made from sodium hydroxide and dipicolinic acid; Aldrich Chemical Co. Inc., Milwaukee Io, Wisconsin) and calcium chloride solution immediately before use in the sodium acetate buffer.

Germination was measured by mixing spores with the media at $37^{\circ}$ and reading extinction of the suspensions at intervals with an absorptiometer ('Biochem', Hilger and Watts Ltd., Camden Road, London). Germination was accompanied by a decrease in extinction. Phase-contrast microscopy was used to confirm germination: ungerminated spores were phase-bright and germinated spores phase-dark.

Alanine analogues. Analogues of the D-isomer used were: D-cycloserine (Oxamycin; D-4-amino-3-isoxazolidone), which was a gift from Eli Lilly and Co. Ltd. (Basingstoke, Hants); $O$-carbamyl-D-serine, a gift from Dr H. P. Hidy (Commercial Solvents Corp., Terre Haute, Indiana); D- $\alpha$-alanyl hydroxamic acid (synthesized by $\mathrm{Mr}$ A. P. Rhodes of this Laboratory). Optically inactive analogues of alanine used were glycyl hydroxamic acid and $\beta$-alanyl hydroxamic acid (Hynes Chemical Research Corp., Durham, North Carolina). Similarities in structure of the analogues are indicated in Fig. I. 
The analogues were dissolved in water and mixed with warmed germination media before use as indicated in Results.

Growth-inhibitory concentrations of alanine analogues. The analogues were sterilized by filtration through sintered glass (grade $I / / 5$ ) and incorporated in nutrient broth at $25 \mathrm{mM}$, and then doubling dilutions were made down to $0.195 \mathrm{~mm}$ by using as diluent broth inoculated with $5 \%(\mathrm{v} / \mathrm{v})$ overnight broth cultures of one of the following organisms: Escherichia coli NCIB 9483 (National Collection of Industrial Bacteria, Torry Research Station, Aberdeen); Pseudomonas aeruginosa; Streptococcus faecalis (laboratory isolates); Staphylococcus aureus OXFORD (NCTC 657I); Bacillus cereus T. The cultures were then incubated at $37^{\circ}$ for $24 \mathrm{hr}$ and the minimum concentrations of analogues inhibiting growth were recorded.

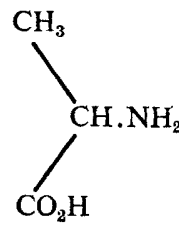

D-Alanine

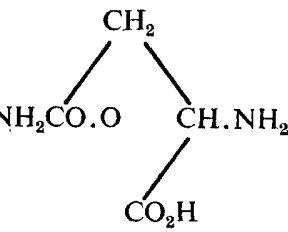

o-Carbamyl-D-serine (OCDS)

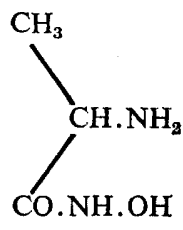

D- $\alpha$-Alanyl hydroxamic acid (DAHA)

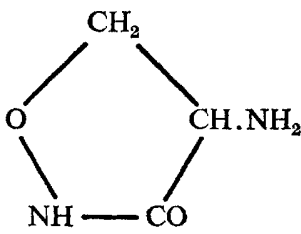

D-Cycloserine (DCS)

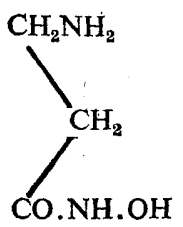

$\beta$-Alanyl hydroxamic acid $(\beta \mathrm{AHA})$

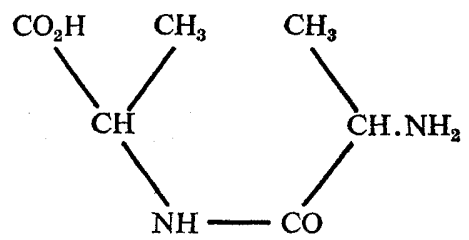

D-Alanyl-D-alanine

Fig. I. Formulae of the alanine analogues studied and of D-alanine and D-alanyl-alanine for comparison. The formulae are written to show similarities of structure.

Alanine racemase. Racemase activity of intact spores was determined by using L-alanine as substrate and measuring the rate of production of D-alanine as described by Fey et al. (1964) with D-amino acid oxidase (from hog kidney, British Drug Houses Ltd., Poole, Dorset; Wood \& Gunsalus, 195I). Incubation mixtures at $37^{\circ}$ contained spores (equiv. I $\mathrm{mg}$. dry weight $/ \mathrm{ml}$.), L-alanine (I00 $\mathrm{mM}) \pm$ analogues, and sodium phosphate $(80 \mathrm{~mm}, \mathrm{pH} 8 \cdot 0)$. At $10 \mathrm{~min}$. intervals up to $60 \mathrm{~min}$., samples $(\mathrm{I} \cdot 5 \mathrm{ml}$.) were removed, cooled in ice, and centrifuged in the cold. D-Alanine formed by racemization was then estimated by incubating samples of the supernatant fluid $(0.5$ ml.) with D-amino acid oxidase (I5 mg.) and sodium phosphate (80 mM, $\mathrm{pH} 8 \cdot 0$ ) in a Warburg apparatus at $30^{\circ}$ and measuring the oxygen uptake for $90 \mathrm{~min}$. Under these conditions $>90 \%$ oxidation of the D-alanine occurred. It was determined separately that none of the analogues used inhibited D-amino acid oxidase nor were they utilized by this enzyme as substrates at the concentrations at which they might be carried over into the Warburg flasks. Inhibition of alanine racemase by analogues is recorded by expressing activity as a percentage of activity of analogue-free controls. 


\section{RESULTS}

\section{Effect of analogues on germination initiated by L-alanine}

Unheated spores of Bacillus cereus $\mathrm{T}$ germinated very slowly in $L$-alanine. The rate of germination was decreased by $D$ - $\alpha$-alanyl hydroxamic acid (DAHA), but the other analogues caused increases in the rates of germination (Fig. 2) in order of increasing activity: $\beta$-alanyl hydroxamic acid ( $\beta$ AHA), D-cycloserine (DCS), glycyl hydroxamic acid (GHA) and $O$-carbamyl-D-serine (OCDS). It was noticeable that the pattern of stimulation of germination by DCS differed from that of the other analogues, showing an increase in rate with time (Fig. 2). Figure 3 shows the result of a similar experiment using heat-activated spores in place of the unheated spores used for Fig. 2. The heated

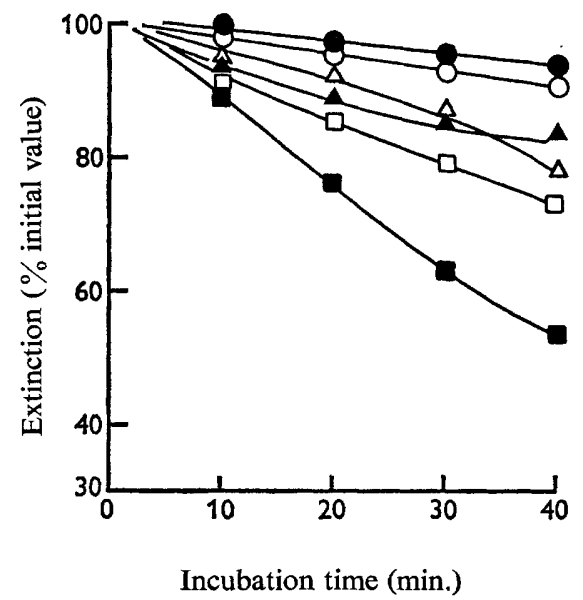

Fig. 2

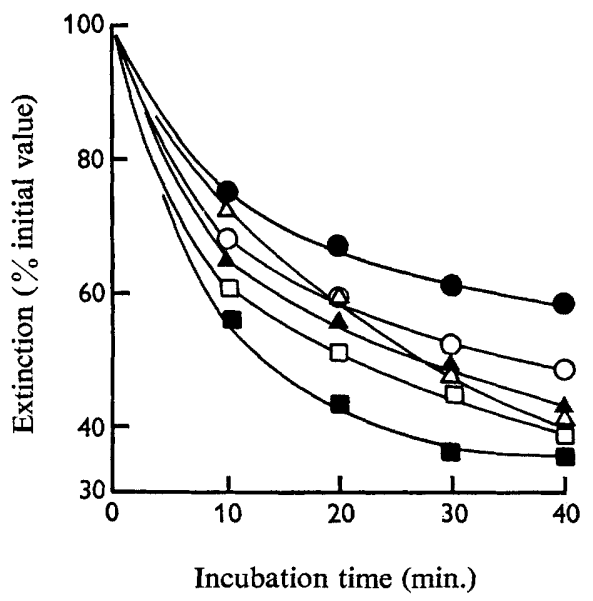

Fig. 3

Fig. 2. Stimulation of germination of unheated spores of Bacillus cereus $\mathrm{T}$ by alanine analogues. All tubes contained L-alanine ( $10 \mathrm{mM}$ ) in sodium phosphate buffer ( $80 \mathrm{mM}, \mathrm{pH} 8.0)$ and were incubated at $37^{\circ}$. Analogues, used at $10 \mathrm{~mm}$ except for $O$-carbamyl-D-serine ( $6 \mathrm{~mm}$ ) were: $\bigcirc$, no analogue added (control);, D-alanyl hydroxamic acid; $\triangle$, D-cycloserine; $\Delta, \beta$-alanyl hydroxamic acid; $\square$. glycyl hydroxamic acid; $\boldsymbol{O}$-carbamyl-D-serine.

Fig. 3. Stimulation of germination of heat-activated spores of Bacillus cereus $\mathrm{T}$ by alanine analogues. Experimental details and symbols as for Fig. 2 except that the spores were heated for $30 \mathrm{~min}$. immediately before use.

B. cereus $\mathrm{T}$ spores germinated more rapidly than the unheated ones, as expected. DAHA again decreased the rate of germination but the other analogues increased the rate of germination, and the late stimulation by DCS was marked. Different rates of germination, but with the same patterns of response, were found with higher and lower concentrations of the analogues and of L-alanine.

\section{Effect of the analogues on germination initiated by germinants other than L-alanine}

Table I summarizes the effects of some of the alanine analogues on germination of spores initiated by the metabolizable germinants inosine, adenosine and L-cysteine and by the non-metabolizable germinants $n$-dodecylamine and calcium dipicolinate (CaDPA). OCDS, the strongest potentiator of alanine-initiated germination, did not 
increase the rate of germination of spores with any of these germinants, strongly suggesting that alanine racemase activity is of little importance in governing germination rate in these systems. DCS inhibited germination of unheated spores in inosine but caused an increase in the initial rate of germination of heat-activated spores. Of the four analogues, only DCS inhibited germination of heat-activated spores in L-cysteine; the other three had no effect. GHA and $\beta$ AHA both stimulated germination induced by inosine or adenosine, most probably because of slight decomposition during incubation (see below) to form glycine or $\beta$-alanine which are synergistic with the riboside germinants.

\title{
Table I. Effect of alanine analogues on germination of Bacillus cereus $T$ spores initiated by various germinants
}

\begin{abstract}
Germination was measured by decrease in extinction of suspension at $37^{\circ}$ as described in Methods. OCDS was used at $6 \mathrm{~mm}$ and the other analogues at $10 \mathrm{~mm}$. None of the analogues was germinative alone.
\end{abstract}

Decrease in extinction (\%) during incubation for $30 \mathrm{~min}$. in the presence of:

\begin{tabular}{|c|c|c|c|c|c|c|}
\hline $\begin{array}{c}\text { Spores } \\
\text { heat-activated } \\
\text { or unheated }\end{array}$ & $\begin{array}{c}\text { Germinant } \\
\text { (concentration) }\end{array}$ & $\begin{array}{l}\text { No } \\
\text { analogue } \\
\text { (control) }\end{array}$ & OCDS & DCS & GHA & $\beta$ AHA \\
\hline $\begin{array}{l}\text { Unheated } \\
\text { Heat-activated } \\
\text { Heat-activated }\end{array}$ & $\begin{array}{l}\text { Inosine }(\mathrm{I} \mathrm{mM}) \\
\text { Inosine }(40 \mu \mathrm{M}) \\
\text { Inosine }(200 \mu \mathrm{M})\end{array}$ & $\begin{array}{l}22 \\
33 \\
69\end{array}$ & $\frac{4}{37}$ & $\frac{6 \cdot 5}{69^{*}}$ & $\begin{array}{l}65 \\
74 \\
-\end{array}$ & $\begin{array}{l}56 \\
55 \\
\end{array}$ \\
\hline Heat-activated & Adenosine (I mM) & 15 & - & - & $3 \mathrm{I}$ & 24 \\
\hline $\begin{array}{l}\text { Unheated } \\
\text { Heat-activated }\end{array}$ & $\begin{array}{l}\text { L-Cysteine (IO mM) } \\
\text { L-Cysteine (Io mM) }\end{array}$ & $\begin{array}{r}9 \\
27\end{array}$ & $\begin{array}{r}8 \\
30\end{array}$ & $\begin{array}{l}4 \\
9\end{array}$ & $\begin{array}{r}4 \\
23\end{array}$ & $\begin{array}{r}6 \\
23\end{array}$ \\
\hline $\begin{array}{l}\text { Unheated } \\
\text { Heat-activated }\end{array}$ & $\begin{array}{l}\text { CaDPA }(40 \mathrm{~mm}) \dagger \\
\text { CaDPA }(40 \mathrm{~mm})\end{array}$ & $\begin{array}{r}4 \\
43\end{array}$ & $\begin{array}{r}2 \\
40\end{array}$ & - & - & - \\
\hline Unheated & $\begin{array}{c}n \text {-Dodecylamine } \\
(\mathrm{I} / 5 \text { satd. }) \dagger\end{array}$ & 42 & 44 & 40 & - & - \\
\hline Heat-activated & $\begin{array}{c}n \text {-Dodecylamine } \\
\text { (I/5 satd.) }\end{array}$ & 43 & 35 & - & - & - \\
\hline
\end{tabular}

* D-Cycloserine consistently caused a slight increase in the initial rate of germination of heatactivated spores in inosine, but this increase was lost after $30 \mathrm{~min}$. incubation.

$\dagger$ Germination initiated by calcium dipicolinate (CaDPA) and $n$-dodecylamine was additionally unaffected by D-alanine (ro $\mathrm{mM}$ ) and by D-alanine (Io mM) + OCDS (6 mM).

\section{Effect of OCDS on germination initiated by combinations of germinants}

Although L-alanine initiates germination of Bacillus cereus $\mathrm{T}$ spores and D-alanine inhibits L-alanine-initiated germination, both the D- and L-isomer will potentiate germination initiated by a germinative riboside like adenosine (Lawrence, 1955). Furthermore, other amino acids, which are not germinative alone, will potentiate the germination caused by a riboside. It was found that OCDS strikingly inhibited the potentiation of adenosine-initiated germination caused by D-alanine whilst hardly affecting potentiation caused by L-alanine (Fig. 4, 5). Similar experiments with $\alpha$-aminobutyric acid, phenylalanine, serine, glycine (Table 2) and other amino acids revealed that the strong inhibition by OCDS of potentiation by $\mathrm{D}$ - but not by L-isomers was typical of alanine but not of other amino acids. Nevertheless, OCDS stimulated germination initiated by adenosine + some of the L-isomers of amino acids other than alanine (Table 2). 


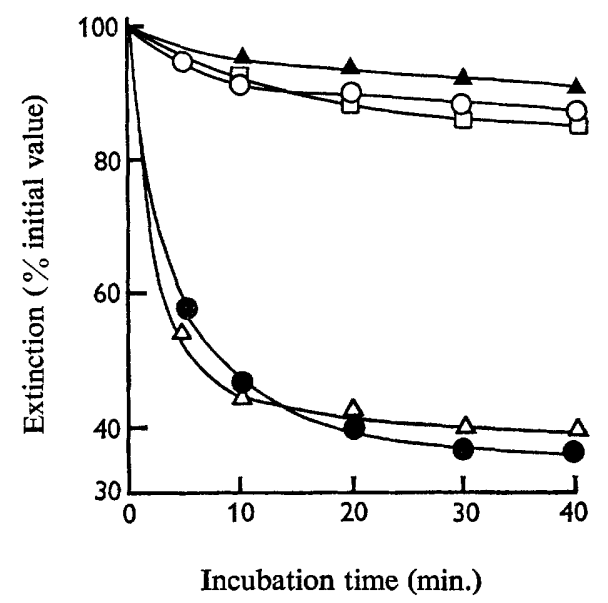

Fig. 4

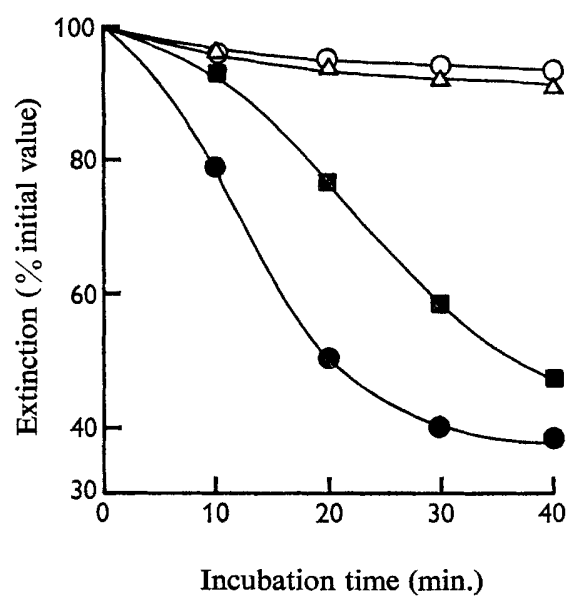

Fig. 5

Fig. 4. Effect of $O$-carbamyl-D-serine (OCDS) on L-alanine-adenosine-initiated germination of Bacillus cereus $\mathrm{T}$ spores. Heat-activated spores were germinated (see Methods) by incubation at $37^{\circ}$ in sodium phosphate buffer $(80 \mathrm{mM}, \mathrm{pH} 8.0)$ containing L-alanine $(100 \mu \mathrm{M})$ and adenosine $(100 \mu \mathrm{M})$ as follows: $\mathrm{O}, \mathrm{L}$-alanine alone; $\boldsymbol{\Delta}$, adenosine alone; $\boldsymbol{\theta}, \mathrm{L}$-alanine + adenosine; $\square$, adenosine + OCDS ( $2 \mathrm{~mm}) ; \triangle$, L-alanine + adenosine + OCDS ( $2 \mathrm{mM}$ ).

Fig. 5. Effect of OCDS on D-alanine + adenosine-initiated germination of Bacillus cereus $\mathrm{T}$ spores. Conditions as for Fig. 4 except that suspensions contained D-alanine (IOO $\left.\mu_{\mathrm{M}}\right)$ and adenosine $(100 \mu \mathrm{M})$ as follows; $O, D$-alanine alone;,$D$-alanine + adenosine; $\triangle, D$-alanine + adenosine + OCDS $(2 \mathrm{mM}) ; \mathbf{0}$, D-alanine + adenosine + OCDS $(100 \mu \mathrm{M})$.

\section{Table 2. Effect of $O$-carbamyl-D-serine on germination of Bacillus cereus $T$ spores initiated by adenosine plus $L$ - and D-amino acids}

Germination was measured as described in Table 1 . The germinant mixture for unheated spores was adenosine ( $\mathrm{I} \mathrm{mM}$ ) + amino acid (IO $\mathrm{mM}$ ), and for heat-activated spores was adenosine $\left(\right.$ IOO $\left.\mu_{\mathrm{M}}\right)+$ amino acid $(\mathrm{I} 00 \mu \mathrm{M})$.

Decrease in extinction $(\%)$ during incubation for $50 \mathrm{~min}$. in the presence of adenosine + amino acid

\begin{tabular}{|c|c|c|c|}
\hline \multicolumn{2}{|c|}{ Unheated spores } & \multicolumn{2}{|c|}{ Heat-activated spores } \\
\hline $\begin{array}{l}\text { OCDS } \\
\text { absent }\end{array}$ & $\begin{array}{c}\text { OCDS } \\
\text { present }\end{array}$ & $\begin{array}{l}\text { OCDS } \\
\text { absent }\end{array}$ & $\begin{array}{c}\text { OCDS } \\
\text { present }\end{array}$ \\
\hline 6 & 7 & 10 & 20 \\
\hline 65 & 65 & 63 & 62 \\
\hline 50 & 13 & 63 & 9 \\
\hline 6I & 6I & 60 & 62 \\
\hline 4 & IO & 55 & 55 \\
\hline $6 \mathrm{I}$ & $6 \mathrm{r}$ & 35 & 57 \\
\hline I & 3 & I & 3 \\
\hline 30 & 47 & 35 & 50 \\
\hline 7 & 7 & I 2 & 26 \\
\hline 20 & 32 & 45 & 53 \\
\hline
\end{tabular}




\section{Stimulation of germination by hydroxylamine}

Stimulation of inosine-initiated germination by GHA and $\beta$ AHA (Table I) might have resulted from partial breakdown of these analogues to form free amino acids because GHA and $\beta$ AHA are known to be less stable than the other analogues in solution (Gale \& Hynes, 1966). To test for breakdown, the analogues were preincubated in solution to allow any decomposition to occur before addition of spores. Also, the potential breakdown products alone were tested as germination stimulators.

Table 3. Inhibition of Bacillus cereus $T$ spore alanine racemase by alanine analogues and hydroxylamine

The racemase assay is described in Methods. Results are expressed as \% of the activity of the racemase acting on $100 \mathrm{mM} \mathrm{L}$-alanine in the absence of the analogues.

\begin{tabular}{|c|c|c|}
\hline Analogue & $\begin{array}{c}\text { Concentration } \\
(\mathrm{mM})\end{array}$ & $\begin{array}{l}\text { Racemase activity } \\
\text { (\% of activity in } \\
\text { analogue-free } \\
\text { control) }\end{array}$ \\
\hline$O$-Carbamyl-D-serine & $\begin{array}{l}100 \\
10 \\
0.5\end{array}$ & $\begin{array}{r}7 \cdot 7 \\
16 \cdot 9 \\
79 \cdot 8\end{array}$ \\
\hline D-Cycloserine & 100 & $35 \cdot 4$ \\
\hline$\beta$-Alanyl hydroxamic acid & $\begin{array}{l}200 \\
100\end{array}$ & $\begin{array}{l}72 \cdot 3 \\
86 \cdot 2\end{array}$ \\
\hline Glycyl hydroxamic acid & $\begin{array}{l}200 \\
100\end{array}$ & $\begin{array}{l}8 I \cdot 6 \\
89 \cdot 2\end{array}$ \\
\hline Hydroxylamine & $\begin{array}{l}\text { IO } \\
\text { I } \\
0 \cdot I\end{array}$ & $\begin{array}{l}28 \cdot 8 \\
55 \cdot 5 \\
94 \cdot 5\end{array}$ \\
\hline
\end{tabular}

Table 4. Stimulation of germination of Bacillus cereus $T$ spores by hydrolysis products of $\beta$-alanyl hydroxamic acid and glycyl hydroxamic acid

Germination of the unheated spores was measured by fall in extinction of suspensions incubated at $30^{\circ}$ with L-alanine (IO mM) as described in Methods.

$\begin{array}{cccc}\begin{array}{c}\text { Hydroxylamine } \\ \text { concentration } \\ (\mathrm{mM})\end{array} & \begin{array}{c}\begin{array}{c}\text { Decrease in extinction }(\%) \text { during incubation for } \\ \text { glycine-free } \\ \text { control }\end{array} \\ \text { 90 min. in the presence of hydrolysis products }\end{array} & \begin{array}{c}\beta \text {-Alanine } \\ \text { (IO mM) }\end{array} & \begin{array}{c}\text { Glycine } \\ \text { (IO mM) }\end{array} \\ \text { IO } & 22 & 22 & 19 \\ 5 & 57 & 60 & 50 \\ \text { I } & 62 & - & - \\ \text { O.I } & 58 & - & -\end{array}$

Pre-incubation did not increase the activity of GHA and $\beta$ AHA as germination stimulants, arguing against the importance of decomposition; however, the observation was made that hydroxylamine, which would be one of the hydrolysis products of the analogues, was a powerful stimulator of L-alanine-initiated germination itself (Table 4). 


\section{Inhibition of alanine racemase by the analogues}

The analogues were tested for ability to inhibit the racemization of alanine catalysed by spores of Bacillus cereus T. Table 3 shows that OCDS was by far the most effective racemase inhibitor, in keeping with its strong activity as a potentiator of L-alanineinitiated germination; next most effective was D-cycloserine, and least effective the hydroxamic acids. Hydroxylamine, in keeping with its stimulatory effect on L-alanineinitiated germination, was a powerful racemase inhibitor.

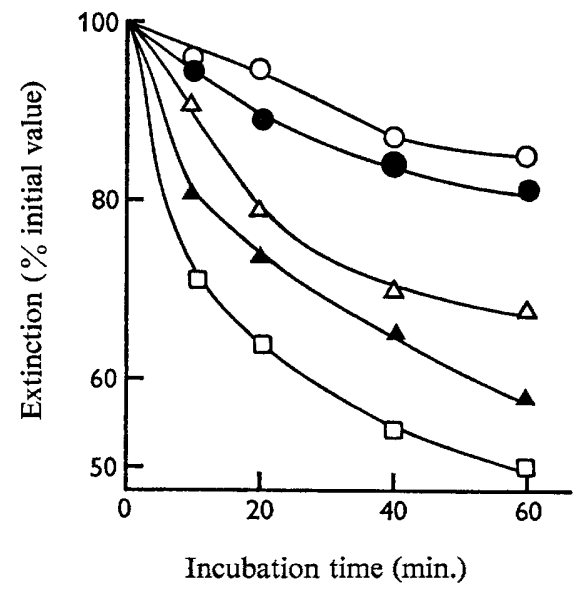

Fig. 6

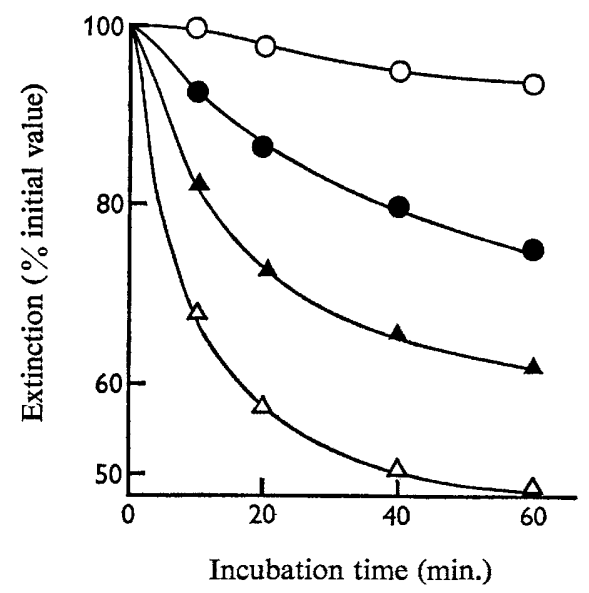

Fig. 7

Fig. 6. Effect of pre-incubating spores of Bacillus cereus $\mathrm{T}$ in the presence of glycyl hydroxamic acid. All tubes contained glycyl hydroxamic acid (10 $\mathrm{mm}$ ) and unheated spores in sodium phosphate buffer ( $80 \mathrm{mM}, \mathrm{pH} \mathrm{8.0)}$ ) and were pre-incubated for various times before L-alanine ( $10 \mathrm{mM}$ ) was added to initiate germination. Pre-incubation times were: $O$, no pre-incubation (spores added with alanine at zero time); $\bullet$, I min.; $\triangle, 5 \mathrm{~min} . ; \Delta, 30 \mathrm{~min}$; $\square, 2 \mathrm{hr}$. Qualitatively similar results were obtained with $\beta$-alanyl hydroxamic acid in place of glycyl hydroxamic acid.

Fig. 7. Binding of $\beta$-alanyl hydroxamic acid to spores of Bacillus cereus $\mathrm{T}$. Unheated spores were preincubated with or without $\beta$-alanyl hydroxamic acid as described in Fig. 6 , then either germinated immediately or washed three times by centrifugation before adding L-alanine (ro $\mathrm{mm}$ ) to initiate germination: $O, \beta$-alanyl hydroxamic acid-free control; $\bullet$, no pre-incubation (spores added with alanine at zero time); $\triangle$, pre-incubation for 120 min.; $\boldsymbol{\Delta}$, pre-incubation for $\mathbf{I} 20 \mathrm{~min}$. followed by three washes. Qualitatively similar results were obtained with glycyl hydroxamic acid in place of $\beta$-alanyl hydroxamic acid.

\section{Binding of $\beta$-alanyl hydroxamic acid and glycyl hydroxamic acid by spores}

The weak inhibition of spore alanine racemase by $\beta$ AHA and GHA (Table 3) was surprising in view of the stimulatory effect of these analogues on L-alanine-initiated germination (Fig. 2 and 3). Evidently the stimulation was not due to hydroxylamine formed by hydrolysis of the analogues, since pre-incubation of the analogues alone did not increase their effectiveness. However, pre-incubation of the spores in the presence of the analogues before addition of L-alanine to initiate germination did result in an increased germination rate (Fig. 6). Furthermore, when spores were pre-incubated with $\beta$ AHA or GHA and then washed to remove exogenous analogue, they still germinated faster in L-alanine than did untreated spores (Fig. 7). These results strongly 
suggested that $\beta$ AHA and GHA, or a product formed from them, could bind to some site in spores during incubation (possibly to molecules of alanine racemase) and thereby be more effective than the simple racemase assay (Table 3 ) would suggest. Pre-incubation of spores with OCDS and DCS also increased their stimulation of L-alanine-initiated germination, but the increase was small compared with that observed with $\beta$ AHA and GHA.

\section{Effect of O-carbamyl-D-serine on germination of spores of different Bacillus species}

Spores of eight strains representing five Bacillus species were incubated in L-alanine (Io mM) with or without OCDS (I mM). It was found that the stimulatory effect of OCDS on germination differed very much with different spores. The Bacillus cereus spores tested responded most readily to the analogue (Table 5). Germination of spores of a number of the organisms shown in Table 5 was stimulated more strongly when thicker suspensions were used (equiv. about I $\mathrm{mg}$. dry wt/ml.), suggesting that stimulation of L-alanine-initiated germination by OCDS was a general phenomenon, although much less marked with some spores than with others.

\section{Table 5. Stimulation of L-alanine-initiated germination of spores of various} Bacillus species by $O$-carbamyl-D-serine

Spores (equiv. about $40 \mu \mathrm{g}$. dry wt $/ \mathrm{ml}$.) were incubated at $37^{\circ}$ in sodium phosphate buffer $(80 \mathrm{mM}) ; \mathrm{pH} 8.0$ ) containing L-alanine (IO mM) and with or without OCDS (I mM). Germination was measured by decrease in extinction of suspensions as described in Methods.

Decrease in extinction (\%) during incubation for $30 \mathrm{~min}$.

Organism $\overbrace{\begin{array}{l}\text { OCDS } \\ \text { absent }\end{array}}^{\text {Unheated spores }} \overbrace{\begin{array}{c}\text { OCDS } \\ \text { present }\end{array}}^{\text {Heat-activated spores }} \overbrace{\begin{array}{l}\text { OCDS } \\ \text { absent }\end{array}}^{\begin{array}{c}\text { OCDS } \\ \text { present }\end{array}}$

B. cereus $\mathrm{T}$
B. cereus $\mathrm{PX}$
B. cereus NCTC 945
B. megaterium
B. subtilis $\mathrm{A}$
B. subtilis (globigii)
B. pumilus $\mathrm{S}$.
B. polymyxa $\mathrm{M}$ I

$\begin{array}{rr}\text { I4 } & 44 \\ \text { IO } & 47 \\ 8 & 39 \\ 6 & \text { I2 } \\ - & - \\ 29 & 34 \\ 37 & 47 \\ 41 & 45\end{array}$

Table 6. Growth-inhibitory activity of the analogues

The analogues were incorporated at $25 \mathrm{~mm}$ and at halving dilutions down to $0.195 \mathrm{~mm}$ in nutrient broth inoculated with the organisms indicated. End-points (no turbidity) were read after incubation for $24 \mathrm{hr}$ at $37^{\circ}$ (see Methods).

Minimum inhibitory concentration ( $\mathrm{mm}$ ) of analogue

\begin{tabular}{lccccc}
\multicolumn{1}{c}{ Organism } & OCDS & GHA & $\beta$ AHA & DCS & DAHA \\
Escherichia coli & $6 \cdot 25$ & $\mathbf{I} 2 \cdot 5$ & 25 & 0.39 & 25 \\
Pseudomonas aeruginosa & $>25$ & 25 & 25 & $3 \cdot 1$ & $12 \cdot 5$ \\
Staphylococcus aureus & 25 & $12 \cdot 5$ & 12.5 & 0.78 & 25 \\
Streptococcus faecalis & $\mathbf{2 5}$ & $>25$ & $>25$ & 3.1 & $>25$ \\
Bacillus cereus T & 25 & 25 & 25 & 0.39 & 25
\end{tabular}




\section{Growth inhibitory activity of the analogues}

The analogues stimulated L-alanine-initiated germination of spores in order of decreasing activity: OCDS, GHA, DCS and $\beta$ AHA; D- $\alpha$-alanyl hydroxamic acid (DAHA) was inactive. It was of interest to compare this order with the growthinhibitory activities of the analogues, since they were originally developed as potential antibiotics. Table 6 shows that the two activities appear superficially to be unrelated. For example, DCS was by far the most effective inhibitor of growth (Table 6), yet not the most effective stimulator of germination; in contrast, OCDS was the most effective stimulator of germination but was relatively ineffective as an inhibitor of growth.

\section{DISCUSSION}

The analogues of alanine studied were originally isolated as antibiotics or synthesized as potential inhibitors of microbial growth. It was therefore surprising to find that they stimulated rather than inhibited germination of bacterial spores. However, the process of spore germination is peculiar in that it is essentially a degradative reaction and involves none of the complex syntheses of growing organisms; it is consequently likely that biochemical sites for inhibition of spore germination by antimicrobial agents are few. Three factors suggest that the analogues studied stimulated spore germination principally by inhibiting spore alanine racemase. First, D-alanine is known to be a powerful competitive inhibitor of germination initiated by L-alanine (Hills, I949). Secondly, spores of some species have been shown to contain an alanine racemase which is often measurably active in the otherwise dormant, i.e. ungerminated, spore (Stewart \& Halvorson, I953), and thick suspensions of spores have been shown to inhibit their own germination in L-alanine by rapidly catalysing production of the inhibitory D-isomer (Fey et al. 1964). Thirdly, both DCS (Strominger, Ito \& Threnn, 1960) and OCDS (Lynch \& Neuhaus, I966) were shown to inhibit alanine racemase in Staphylococcus aureus and Streptococcus faecalis respectively. DCS and OCDS also inhibited alanine racemase in Bacillus cereus spores (Table 3), and therefore most probably potentiated germination by this action. Further evidence was given by Krask (I96I), who showed that D-cysteine (which may be regarded as another 'analogue' of D-alanine) potentiated L-alanine-initiated germination of $B$. cereus $\mathrm{T}$ spores and also inhibited spore alanine racemase. Stimulation of germination of thick spore suspensions by copper may also have resulted from inhibition of alanine racemase (Powell, 1957).

The two analogues $\beta$ AHA and GHA are antimycobacterial agents that may act in a similar manner to DCS and OCDS in inhibiting microbial growth (Gale \& Hawkins, 1965; Gale \& Hynes, 1966). However, they were much less effective inhibitors of spore alanine racemase than DCS or OCDS. The surprisingly powerful stimulation of spore germination by $\beta$ AHA and GHA seemed to result from binding of these analogues during incubation with the spores. Additional stimulation by formation of hydroxylamine from the analogues in the presence of spores cannot be completely ruled out, for hydroxylamine was shown by Roze \& Strominger (I966) to inhibit alanine racemase in Staphylococcus aureus more effectively than even D-cycloserine, and was also an effective inhibitor of alanine racemase and stimulator of germination in spores of Bacillus cereus T (B. J. Krask, personal communication; and Table 3). D- $\alpha$-Alanyl hydroxamic acid (DAHA) was tested because it appeared to be a better 
structural analogue of D-alanine than either $\beta$ AHA or GHA (Fig. 1), and yet its activity both as an antimicrobial agent and as a potentiator of L-alanine-initiated germination was unaccountably negligible.

The effects of alanine racemase inhibitors on germination initiated by single germinants other than L-alanine (e.g. ribosides, L-cysteine or other amino acids) were in keeping with non-involvement of the racemase, and also therefore presumably of endogenously formed L-alanine, in the metabolic pathways involved. For instance, the results argue against inosine as initiating germination by somehow triggering release of L-alanine within the spore. Krask \& Fulk (I966) showed that germination of spores of Bacillus cereus $\mathrm{T}$ by L-cysteine did not involve formation of $\mathrm{L}$-alanine from the cysteine, but more likely resulted from action of L-alanine dehydrogenase directly on the L-cysteine molecules; the spore enzyme is not completely specific for L-alanine (O'Connor \& Halvorson, I96I $a$ ) and germination can be initiated by the other substrates of the enzyme (O'Connor \& Halvorson, I96 $b$; Hermier \& Rousseau, I967). In such a situation one would not expect inhibition of alanine racemase to lead to stimulation of germination.

Although OCDS stimulated the germination initiated by L-alanine and had little effect on germination initiated by adenosine $+\mathrm{L}$-alanine, it strongly inhibited the germination initiated by adenosine $+\mathrm{D}$-alanine. This result suggested that the role of D-alanine was solely to supply L-alanine and that the L-isomer was the true synergist with adenosine; when the racemase was inhibited by OCDS no L-isomer was formed and germination was therefore arrested. OCDS did not effect germination initiated by adenosine + amino acids other than alanine in this clear cut manner. In general, OCDS slightly stimulated such germination, as it did the slow germination caused by adenosine alone (Table 2); OCDS certainly did not inhibit the activity of the D-isomers, thus suggesting that $\mathrm{D}$-alanine was not an intermediate in their utilization. Lack of effect of the analogues on germination initiated by $n$-dodecylamine or calcium dipicolinate supports the concept that these reagents are not metabolized, but initiate germination by causing physico-chemical changes in spores (Rode \& Foster, I96I ; Riemann \& Ordal, 196I).

It was interesting to find that high antibacterial activity of an analogue did not necessarily accompany high activity as a potentiator of L-alanine-initiated germination. The reason for this is probably that, whereas potentiation of germination depends principally (if not entirely) on the antiracemase activity of the analogues, the antibacterial activity depends additionally on inhibition of other enzymes which are normally involved in murein synthesis in growing organisms. For example, DCS powerfully inhibited not only alanine racemase but also D-alanyl-D-alanine synthetase (Strominger et al. 1960); inhibition of these two sequential enzymic steps in murein synthesis conferred high antibacterial activity on DCS. In contrast, OCDS inhibited spore alanine racemase more effectively than did DCS and was consequently a better potentiator of L-alanine-initiated germination; yet OCDS did not inhibit D-alanyl-Dalanine synthetase (Lynch \& Neuhaus, 1966) and was therefore relatively less active than DCS as an antibacterial agent. Perhaps the free carboxyl group on OCDS but not on DCS contributed to antiracemase activity since OCDS is structurally closer to the free D-alanine substrate of the racemase than is DCS or the other analogues (Fig. I). In contrast, DCS contains no free carboxyl group but a $-\mathrm{NH}-\mathrm{CO}-$ link analogous to the peptide bond region of D-alanyl-D-alanine and is therefore a better 
analogue of the dipeptide whose synthesis it inhibits than is OCDS. The relationships of structure of these analogues to their antibiotic activity was reviewed by Neuhaus (I967). It may be that more effective potentiators of germination could be discovered by extension of these studies with spores, but it is clear that there is no reason to assume that such potentiators would also necessarily be more effective as antibacterial agents.

\section{REFERENCES}

Church, B. D., Halvorson. H. \& Halvorson, H. O. (1954). Studies on spore germination: its independence from alanine racemase activity. J. Bact. 68, 393.

EDWARDS, J. C., Busta, F. F. \& SPECK, M. L. (1965). Thermal inactivation characteristics of Bacillus subtilis spores at ultra high temperatures. Appl. Microbiol. 13, 85 I.

FEY, G., Gould, G. W. \& HITCHINS, A. D. (1964). Identification of D-alanine as the auto-inhibitor of germination of Bacillus globigii spores. J. gen. Microbiol. 35, 229.

Freeze, E. \& CASHEL, M. (1965). Initial stages of germination. In Spores, ed. by L. L. Campbell and H. O. Halvorson, vol. 3, p. I I4. Ann Arbor, Michigan: American Society for Microbiology.

GALE, G. R. \& HaWkins, J. E. (1965). Antimycobacterial properties of glycyl hydroxamic acid and $\beta$-alanyl hydroxamic acid. Am. Rev. resp. Diseases 92, 642.

GaLE, G. R. \& HyNes, J. B. (I966). Further studies of the antimycobacterial agents glycyl hydroxamic acid and $\beta$-alanyl hydroxamic acid. Can.J. Microbiol. 12, 73.

GouLD, G. W. (1966). Stimulation of L-alanine-induced germination of Bacillus cereus spores by D-cycloserine and $O$-carbamyl-D-serine. J. Bact. 92, I261.

Hermier, J. \& Rousseau, M. (1967). La germination de la spore de Bacillus subtilis. IV. Role des acides aminés dans la perte de refringence de la spore. Annls. Inst. Pasteur, Paris rr3 327.

Hitchins, A. D., Gould, G. W. \& HuRst, A. (I963). The swelling of bacterial spores during germination and outgrowth. J. gen. Microbiol. 30, 445 .

HILls, G. M. (1949). Chemical factors in the germination of spore-bearing aerobes. Effect of amino acids on the germination of Bacillus anthracis, with some observations on the relation of optical form to biological activity. Biochem. J. 45, 363 .

HILls, G. M. (1950). Chemical factors in the germination of spore-bearing aerobes. Observations on the influence of species, strain and conditions of growth. J. gen. Microbiol. 4, 38.

KrASK, B. J. (196I). L-Alanine dehydrogenase in spores. Discussion in Spores, ed. by H. O. Halvorson, vol. 2, p. 89. Minneapolis, Minnesota: Burgess Publishing Co.

Krask, B. J. \& FulK, G. E. (1966). Enzyme locus: a factor in Bacillus cereus spore germination independence from L- and D-cysteine desulphydrase activities. Bact. Proc. p. 32.

LAWRENCE, N. L. (1955). The cleavage of adenosine by spores of Bacillus cereus. J. Bact. 70, 577.

LYNCH, J. L. \& Neuhaus, F. C. (1966). On the mechanism of action of the antibiotic $O$-carbamyl-Dserine in Streptococcus faecalis. J. Bact. 9r, 449.

Neuhaus, F. C. (1967). D-Cycloserine and O-carbamyl-D-serine. In Antibiotics: Mechanism of Action. Ed. by D. Gottlieb and P. D. Shaw, vol. I, p. 40. New York: Springer Verlag.

O'ConNor, R. J. \& HaLvorson, H. O. (196I $a$ ). The substrate specificity of L-alanine dehydrogenase. Biochim. biophys. Acta 48, 47.

O'CoNNOR, R. J. \& HALvorson, H. O. (196I b). L-Alanine dehydrogenase: a mechanism controlling the specificity of amino acid-induced germination of Bacillus cereus spores. J. Bact. 82, 706.

Powell, J. F. (1957). Biochemical changes occurring during spore germination in Bacillus species. J. appl. Bact. 20, 349.

RIEMANN, H. \& ORDAL, Z. J. (I96I). Germination of bacterial spores with calcium and dipicolinic acid. Science, N.Y. $\mathbf{1 3 3}, \mathbf{1} 703$.

RODE, L. J. \& Foster, J. W. (I96I). Germination of bacterial spores with alkyl primary amines. J. Bact. 81, 768 .

Roze, U. \& STrominger, J. L. (1966). Alanine racemase from Staphylococcus aureus: Conformation of its substrates and its inhibitor; D-cycloserine. J. molec. Pharmacol. 2, 92.

Stewart, B. T. \& Halvorson, H. O. (1953). Studies on the spores of aerobic bacteria. I. The occurrence of alanine racemase. J. Bact. $65,160$.

Strominger, J. L., Ito, E. \& Threnn, R. H. (1960). Competitive inhibition of enzymatic reactions by Oxamycin. J. Am. chem. Soc. 82, 998.

Wood, W. A. \& Gunsalus, I. C. (I95I). D-Alanine formation: a racemase in Streptococcus faecalis. J. biol. Chem. r9o, 403. 